\title{
Editorial
}

\author{
FRANCOISE BLIN
}

Dublin City University, Ireland

We are particularly delighted to begin the first issue of Volume 20 with Tatsuya Nakata's EUROCALL Research Award 2007 winning article. Nakata's study of vocabulary learning presents all the attributes of a solid piece of research and is a model for future applicants. As part of her prize, Tatsuya Nakata will be invited to attend the EUROCALL 2008 Conference in Székesfehérvár, Hungary. She will also get one year's free membership of EUROCALL.

Having been suspended for some years, the EUROCALL Research Award was reinstated last year as part of a range of initiatives to encourage new and 'old' researchers to submit an original article for publication in ReCALL. Other initiatives include our efforts, and in particular those of June Thompson, the EUROCALL President Ana Gimeno, and Cambridge University Press, to get ReCALL included in research indexes and databases, such as Thomson Scientific and ERIC. An agreement between ERIC and EUROCALL has already been signed, which will ensure that materials published in ReCALL and in the EUROCALL Review can be easily retrievable through ERIC. At a time when research metrics are penetrating all disciplines, countries and institutions, these developments should ensure the visibility, dissemination and recognition of the excellent work carried out by CALL researchers around the world and more specifically by our authors.

Among the other six articles published in this issue, five are selected papers from the EUROCALL 2006 Conference in Granada. All reflect the broad range of research questions and innovative approaches to the study of emerging phenomena in our field as well as the breadth of activities carried out by CALLers around the world. In her article

1. The prize includes a free registration at the next EUROCALL conference but excludes accommodation and travel costs. It must be taken up within one year of the Award. For Terms and Conditions, please refer to the EUROCALL website: http://www.eurocall-languages.org/research/research_award.html). 
on language testing and technology, Patricia Doohey explores issues of validity, reliability and practicality in relation to computer-based testing and new insights on vocabulary acquisition and knowledge retention are provided by Absalom's comparative study of online listening versus online text-based tasks. New theories and paradigms are called upon to assist our understanding of emerging technologies. For example, Lund expertly uses activity theory and bakhtinian concepts to shed new and inspiring insights on collective language production in wikis, while Murray and Hourigan look at the use of blogs in language teaching according to two different paradigms, expressivism and socio-cognitivism. Drawing on genre theory and functional linguistics, Lirola further proposes new avenues to examine the relationship between development of learners' written competence and computer-assisted error correction. Finally, in one of two articles (the second one being published in the EUROCALL Review), Coniam examines chatbots and their potential for ESL.

\section{Reviewers for Volume 19}

The editors would like to thank the following reviewers for their contribution to the preparation of Volume 19:

Anthony Baldry, Ylva Berglund, Sabine Braun, Angela Chambers, Thierry Chanier, Jean Conacher, Graham Davies, Robert Debski, Wilfried Decoo, Fiona Farr, John Gillespie, Ana Gimeno, Michael Goethals, Trude Heift, Dominique Hémard, MarieMadeleine Kenning, Marie-Noëlle Lamy, Michael Levy, David Little, Michael McCarthy, Sue Otto, Kazumi Sakai, Mathias Schulze, Lesley Shield, Glenn Stockwell, Peppi Taalas, Maija Tammelin, Dieter Wolff. 